\title{
Regenerative Approaches as Alternatives to Donor Allografting for Restoration of Corneal Function
}

\author{
May Griffith, Naresh Polisetti, Lucia Kuffova, Juana Gallar, John Forrester, \\ Geeta K Vemuganti and Thomas Armin Fuchsluger
}

\section{Linköping University Post Print}

N.B.: When citing this work, cite the original article.

Original Publication:

May Griffith, Naresh Polisetti, Lucia Kuffova, Juana Gallar, John Forrester, Geeta K Vemuganti and Thomas Armin Fuchsluger, Regenerative Approaches as Alternatives to Donor Allografting for Restoration of Corneal Function, 2012, The Ocular Surface, (10), 3, 170-183.

http://dx.doi.org/10.1016/j.jtos.2012.04.004

Copyright: Elsevier

http://www.elsevier.com/

Postprint available at: Linköping University Electronic Press

http://urn.kb.se/resolve?urn=urn:nbn:se:liu:diva-81835 
SECTION: Clinical Science, J. Daniel Nelson, MD, Editor

TITLE: Regenerative Approaches as Alternatives to Donor Allografting for Restoration of Corneal Function

May Griffith, $\mathrm{PhD},{ }^{1}$ Naresh Polisetti, $\mathrm{PhD}^{1}$ Lucia Kuffova, $\mathrm{MD}, \mathrm{PhD},{ }^{2}$ Juana Gallar, MD, PhD, ${ }^{3}$ John Forrester, FARVO, ${ }^{4}$ Geeta Vemuganti, MD, DNB, FAMS, ${ }^{5}$ and Thomas Armin Fuchsluger, $\mathrm{MD}, \mathrm{FEBO}, \mathrm{MSc}^{5}$

\section{SHORT TITLE: Regenerative Approaches to Corneal Reconstruction/Griffith et al}

\section{FOOTNOTES}

Accepted for publication April 2012.

From the ${ }^{1}$ Integrative Regenerative Medicine (IGEN) Centre, Department of Clinical and Experimental Medicine, Linköping University, Sweden, ${ }^{2}$ Section of Immunology and Infection (Ocular Immunology), Division of Applied Medicine, University of Aberdeen, Scotland, United Kingdom, ${ }^{3}$ Instituto de Neurosciencias. Universidad Miguel Hernandez, Alicante, Spain, ${ }^{4}$ Department of Ophthalmology, University of Aberdeen, Scotland, United Kingdom, ${ }^{5}$ School of Medical Sciences, University of Hyderabad, Hyderabad, India, and ${ }^{6}$ Department of Ophthalmology, Heinrich-Heine-University, Duesseldorf, Germany.

Financial support for clinical research reported on biosynthetic corneas for regenerative application are from research grants from the Swedish Research Council, County Council of Östergötland, Sweden and the Canadian Stem Cell Network. Other research data generated from authors were supported by research grants from their own countries, including NSERC Canada (MG).

\section{Disclosures:}

A patent application related to the biomaterials formulation described in this study has been filed and assigned to the Ottawa Hospital Research Institute (OHRI) and is currently licensed to Eyegenix Inc., a wholly owned subsidiary of Cellular Bioengineering. None of the authors have current affiliations or activities related to Eyegenix/Cellular Bioengineeringnor the product discussed in this article. (AU: Please confirm that this statement is correct, or insert appropriate disclosures.) 
Single-copy reprint requests to May Griffith, $\mathrm{PhD}$ (Address below).

Corresponding Author: May Griffith, $\mathrm{PhD}$, Dept. of Clinical and Experimental Medicine, Linköping University, Cell Biology Building, Level 10, 58185 Linköping, Sweden. Tel: +46 (0) 28 1756 or +46 (0)10 103 4254. Mobile: +46 (0) 73656 9375. E-mail: May.Griffith@liu.se.

\title{
AU: Please provide abstract and key words.
}

Key words: cornea transplantation, keratoprostheses, biomaterial scaffolds, stem cells, regeneration,

\begin{abstract}
A range of alternatives to human donor tissue for corneal transplantation are being developed to address the shortfall of good quality tissues as well as the clinical conditions in which allografting is contraindicated. Classical keratoprostheses, more commonly referred to as artificial corneas have been around and are being used clinically to replace minimal corneal function, but only as last resorts, as they are still associated with significant in vivo complications, such as extrusion/rejection, glaucoma, or retinal detachment. In the past few years, there have been many significant developments in technologies that are designed to replace part or the full thickness of damaged or diseased corneas that encourages regeneration to different extents. In this review, we describe selected examples from the range of these corneal substitutes that range from keratoprostheses with regenerative capabilities through tissue-engineered scaffolds pre-seeded with stem cells to cell-based regenerative strategies. It is unlikely that there will be one best corneal substitute for all indications, but taken together, the various approaches may soon be able to supplement the supply of human donor corneas for transplantation, or allow restoration of diseased or damaged corneas that cannot be treated by currently available techniques.
\end{abstract}




\section{Outline}

I. The case for developing regeneration medicine approaches for corneal reconstruction

II. Keratoprostheses and biointeractive implants with regenerative functions
A. Design aspects of regenerative keratoprostheses

B. Examples of keratoprostheses with regenerative capabilities

III. Biomaterials-enhanced cell-based regeneration
A. Biopolymeric and biomimetic scaffolds for promoting regeneration
B. Hybrid scaffolds and nanocomposites for promoting regeneration
C. Decellularized corneas as scaffolds

IV. Cell-based regenerative therapies
A. Corneal epithelial reconstruction
B. Biomaterials-assisted carrier-free transplantation of corneal cell sheets
C. Corneal endothelial reconstruction
D. Multi-layer tissue-engineered constructs

V. Immunological considerations

VI. Reinnervation of biointeractive implants

VII. Conclusions

I. The case for developing regenerative medicine approaches for cornea reconstruction (AU: Heading ok as revised? Yes)

Diseases affecting the cornea are a major cause of blindness world-wide, second only to cataract in overall importance. ${ }^{1}$ A range of infectious and inflammatory eye conditions affects the transparency of the cornea and can ultimately lead to corneal blindness. According to the World 
Health Organizations' (WHO; Geneva, Switzerland) definition of blindness, it is estimated that number of people with visual impairment (presenting vision) is 285 million (65\% of whom are aged over 50 years). Of these, 246 million have low vision (63\% over 50) and 39 million are estimated to be blind ( $82 \%$ over 50 ). Infectious conditions such as trachoma and corneal ulcer are common in the developing world, whereas non-infectious and infectious entities like corneal dystrophies, pseudophakic bullous keratopathy and herpetic eye disease are more common causes of corneal blindness in developed countries. ${ }^{2-6}$

Many corneal diseases are treatable by transplantation using donated corneal tissue by penetrating keratoplasty, lamellar keratoplasty, or endothelial keratoplasty. However, success is limited in conditions that involve corneal nerve damage, such as trauma or infection (bacteria, fungal or viral); or pathologies that chronically disrupt the ocular surface mucosa (ocular cicatricial pemphigoid and Stevens-Johnson's syndrome) or disrupt tear production (Sjögren syndrome) or injuries (severe chemical and thermal burns) that destroy the limbal stem cell niches (limbal stem cell deficiency [LSCD]). Allotransplantation has a poor prognosis also in eyes with corneal dystrophy if there has been a previously rejected graft. Furthermore, the infrastructure necessary for a corneal transplant service is not available in many parts of the world, even in some developed countries, ${ }^{8}$ because of limitations in the facilities for storage and distribution of corneal tissue or insurgical training and availability of surgeons, or because of cultural or religious barriers. Even with available donor tissues, the success rate for transplantation beyond the first few years is relatively low. The overall rate of graft rejection and failure with 24 months of transplantation is $10 \%$ in Sweden, a developed country, ${ }^{9}$ and is about $50 \%$ in Australia after 5 years posttransplantation, ${ }^{7}$ although it should be noted that the Australian cases comprised high-risk grafts. ${ }^{7}$.

The risk of transmitting infection through corneal transplantation must also be considered. While extremely rare, this potential exists, and hence all donated corneas are screened at very high costs. Person-to-person transmission of the rabies virus ${ }^{10}$ and at least one case of Creutzfeldt-Jakob disease ${ }^{11}$ have been reported. Another concern is that yet unknown pathogens could be transmitted.

Within the past few years, significant developments have occurred in biomaterials and stem cell-based methods and combinations of both for use in replacing part or the full thickness of damaged or diseased corneas. Thus, other methodologies, such as regeneration of the ocular surface and other affected layers, have become important alternatives to conventional transplantation techniques. The best-known alternatives to human corneal allografts are "artificial corneas," a term applied to corneal prostheses or keratoprostheses (KPro's). Classical KPro's were developed using plastic-based materials and were designed to restore minimal light transmission and protective 
functions of the cornea. ${ }^{12,13}$ These devices have now been used clinically but only as last resorts, as they are still associated with significant in vivo complications, such as extrusion/rejection, glaucoma, or retinal detachment. A number of reviews have addressed the use of traditional

KPro's. ${ }^{14-16}$ This review focuses on the regenerative approaches to restoration of corneal function, since these represent possible current and future alternatives to conventional donor transplantation.

\section{Keratoprostheses and Biointeractive Implants with Regenerative Functions}

In contrast to conventional KPro's, such as $\mathrm{OOKP}^{17}$ or Boston KPro, that do not necessarily have to show epithelialized surfaces, it has been argued that with keratoprostheses designed to allow for partial regenerative function, epithelial regeneration is the most important factor for reducing post-operative complications. Those complications are mainly infections that are prevented by restoration of the eye's natural cellular barrier to external contaminants. For epithelization to occur, regenerative KPro's require a surface that supports the adhesion of cells, while being sufficiently permeable to nutrients, primarily glucose, to maintain the health of an overlying epithelium. ${ }^{14}$

\section{A. Design Aspects of Regenerative KPro's}

Permeability, of minor relevance to conventional KPro's, has been made possible by development of new hydrogel materials with high water content similar to that of natural corneas. These materials include ionic copolymers of poly(2-hydroxyethyl methacrylate [PHEMA]), ${ }^{17,} 18$ intrinsically higher water content homopolymers like poly(vinyl alcohol [PVA]), ${ }^{19,20,21}$ and hydrophilic double polymer networks of polyethylene glycol (PEG) and poly(acrylic acid) (PAA). ${ }^{14,22}$

In both cases, however, extracellular matrix macromolecules and/or growth factors or derivatives are often applied as surface coatings to promote regeneration. Naturally occurring extracellular matrix proteins, such as collagen, fibronectin, and laminin, and derivative cell adhesive peptides such as IKVAV, YIGSR and RGD, have been grafted onto the KPro's, ${ }^{17,18,23-25}$ although other factors including pore size and surface topography ${ }^{26}$ can also impact device epithelization. Although results have not been entirely confirmed in an in vivo model, in vitro work suggests that corneal epithelial cell growth and adhesion were significantly enhanced by tethering of laminin or fibronectin adhesion-promoting peptide (FAP) via flexible poly(ethylene) glycol (PEG) chains, more so than by tethering of fibronectin or simple coating of the surface with matrix 
proteins. ${ }^{17,18}$ In several studies, modification with fibronectin-based $\operatorname{RGD}(\mathrm{S}),{ }^{27,28,29}$ laminin-based YIGSR, ${ }^{24,25}$ and a novel collagen-based peptide Gly-Pro-Leu ${ }^{26}$ have been observed to improve epithelial cell adhesion to various surfaces in vitro. Surface modification with combinations of peptides, including the cell adhesion peptides RGDS and YIGSR as well as synergistic counterparts PHSRN and PDSGR, demonstrated that corneal epithelial cell adhesion is greatly improved on surfaces with the cell adhesion peptides and at least one of the counterparts. ${ }^{25}$

Another strategy to improve epithelialization involves the use of growth factors. In particular, epidermal growth factor (EGF) is a potent stimulator of corneal epithelial cell proliferation and migration, and is active in the wound healing process. The covalent binding of EGF to poly(dimethylsiloxane) (PDMS) substrates via a PEG tether has been shown to significantly improve cell coverage of the polymer in vitro. ${ }^{30}$ This is likely correlated to the significantly greater production of various extracellular matrix (ECM) proteins required for cell adhesion. Interestingly, modification with growth factor/ECM peptide combinations did not lead to significant increases in epithelization in vitro despite expected amounts of peptide and growth factor on the surface. Clearly, the interactions between the growth factor-modified polymer and the cells are complex and require further study but have significant potential to alter epithelization of KPro's materials.

Underlying surface modifications also appear to play a role in the extent of cell coverage, as well as the density of EGF on the surface and the presence of EGF in the cell culture medium. In contrast to stimulatory effects, epithelial cell attachment to certain parts of the keratoprosthesis must be inhibited to prevent epithelial downgrowth and retroprosthetic membrane formation.

Transforming growth factor beta (TGFß) was investigated because of its previously demonstrated ability to inhibit epithelial growth and promote stromal keratocyte proliferation, hence its potential usefulness for modification of the stromal implant surface. However, the results observed on TGF $\beta$ modified PDMS surfaces in vitro were opposite to those expected; keratocyte adhesion was inhibited and epithelial cell growth was enhanced by surface treatment, indicating the complex nature of growth factor-cell interactions. ${ }^{31}$ Grafting of PEG to poly(methyl methacrylate) (PMMA) implants, which typically exhibit high protein deposition and cell adhesion associated with retroprosthetic membrane formation, was investigated. ${ }^{32}$ The modification resulted in decreased keratocyte and inflammatory cell adhesion on the polymer surface in vitro and in rabbit experiments. 


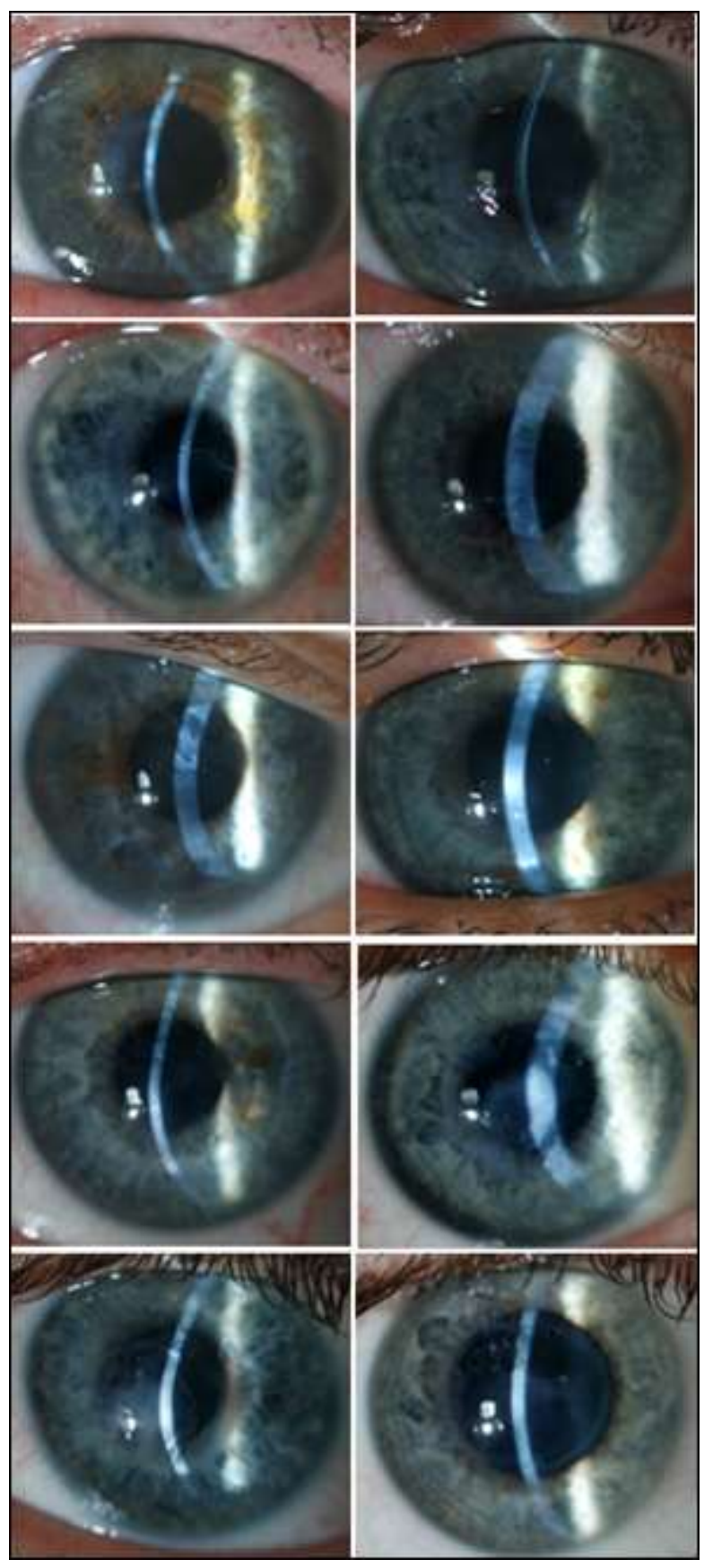

Figurre 1. Slit lamp biomicroscopy photographs of recombinant human collagen implants 24 months after being placed into human corneas. Implants were well integrated into recipient corneas, with implant boundaries barely visible. Focal areas of haze were noted to varying degrees in eight patients at 24 months, whereas corneas were transparent outside these areas. Two corneas were completely haze-free at 24 months (right column, first and third rows). (Reprinted from Fagerholm $\mathrm{P}$, et $\mathrm{al}^{39}$ with permission of the American Association for the Advancement of Science.) 


\section{B. Examples of KPro's with regenerative capabilities}

Jacob and coworkers coupled cell adhesion peptides and various cytokines to poly (methacrylic) acid-co-2-hydroxyethyl methacrylate (PHEMA/MAA). ${ }^{18}$ The addition of methacrylic acid monomers to PHEMA has the effect of increasing the water content to over $70 \%$ and, in turn, increasing the permeability of the hydrogel. They found that in vitro, corneal epithelial outgrowth was greatly enhanced on these substrates when laminin and fibronectin adhesion-promoting peptide were tethered to their surface via flexible PEG chains. Of notable importance is that the peptides and factors are exposed to biodegradation, and therefore, effort must be made to ensure that longterm attachment of the epithelial cells on the surface is maintained.

Myung and coworkers reported on a KPro consisting of a double network of PEG and PAA. ${ }^{14}$ A recent version comprised of a photo-lithographically patterned device with a PEG/PAA central core and a poly (hydroxyethyl acrylate) (PHEA) micro-perforated skirt. Coupling of collagen type I to the hydrogel allowed for epithelial coverage in wound healing models both in vitro and in vivo in rabbits. ${ }^{33}$ The latest iteration, comprising a single-piece KPro fabricated using a 2-step polymerization process is under investigation. First, a core-skirt construct is fabricated by photolithographic polymerization of PEG. This is followed by sequential polymerization and crosslinking of acrylic acid within the bulk of the PEG form.

\section{Biomaterials-enhanced cell-based regeneration}

\section{A. Biopolymeric and Biomimetic Scaffolds for Promoting Regeneration}

While cell growth in two dimensions has been demonstrated on the surfaces of many synthetic polymers, ingrowth or encapsulation (three-dimensional growth) of living cells has been demonstrated only in a few, fully synthetic polymers, particularly poly(ethylene) oxide,

poly(propylene) oxide, and poly(N-isopropyl acrylamide) (PNiPAAm). ${ }^{34,35}$ In contrast, many natural biopolymer hydrogels, such as those based on alginate, fibrinogen-fibrin, chitosan, agarose, albumin, collagens, and their derivatives, are widely used to encapsulate living cells. Hydrogels of collagen type I, the predominant biopolymer in the human cornea, are particularly attractive as matrix replacement scaffolds, partly because of their strength at relatively low concentrations, resulting from the virtually rigid rod properties of the collagen type I triple helix. ${ }^{36}$ In addition, collagen brings the cell attachment motif arginine-glycine-glutamic acid (RGD). ${ }^{37}$ However, both the biodegradation resistance of collagen type I and the strength of hydrogels in general at low concentrations $(10 \% \mathrm{wt} / \mathrm{vol})$ need to be enhanced by chemical crosslinking. ${ }^{35}$ 
To date, only EDC and NHS crosslinked recombinant human collagen corneal substitutes have been tested in humans in a phase I clinical study in Sweden as lamellar grafts in 10 patients. ${ }^{38}$ Rationale has been to find a suitable substitute for human donor corneas, given the long waiting time in Sweden. In a proof of principle setting, lamellar and not full-thickness grafts have been chosen for transplantation. Six-month postoperative results showed regeneration of epithelium and ingrowth of stromal cells, anchoring the implants. Most significantly, as in animal studies that used healthy specimens, nerve regeneration was observed within these corneal implants. ${ }^{38}$ Two-year clinical results ${ }^{39}$ showed that implants have been stably retained without clinically observed adverse immune reactions, and therefore are suitable as temporary grafts or patches. Six of the ten patients had also improved vision. Nine of the ten experienced corneal tissue, nerve, and tear film regeneration, meaning that corneal epithelial cells grew over the implant while stromal cell and nerves grew into the implant (Figure 2). Restoration of the tear film may have allowed contact lensintolerant patients to return to normal contact lens wear for optical purposes. At four years postoperative, all implants remained stably integrated without the use of immunosuppression. However, longer-term monitoring and more extensive testing is needed to determine whether recombinant human collagen corneal substitutes are suitable as donor allografted tissue.

\section{B. Hybrid Scaffolds and Nanocomposites for Promoting Regeneration}

Although cross-linked collagen-only implants are adequately robust for suturing, their mechanical properties are insufficient to provide normal corneal tensile strength. However, strength can be improved by either co-polymerization with a synthetic network, or by introducing a second network, eg, as interpenetrating networks (IPNs). For example, a novel PNiPAAm-based polymer (poly (N-isopropylacrylamide-co-acrylic acid-co-acryloxysuccinimide) or its YIGSR-modified analog (co-polymers abbreviated to Terpolymer (TERP) and TERP5, respectively), was copolymerized with type I bovine atelocollagen to provide transparent hydrogels that were moldable to the curvature and dimensions of a normal cornea. ${ }^{40}$ Collagen TERP5 hydrogels were implanted as lamellar grafts into host pig cornea with pig cornea allografts used as controls. This study reported for the first time the regrowth of corneal epithelial and stromal cells onto and into the implant, respectively, to reconstitute corneal tissue. This was accompanied by restoration of tear film mucin and regeneration of corneal nerves with concomitant recovery of touch sensitivity by 6 weeks post-operation. In contrast, allografted controls had no innervation or sensitivity within this period. Previous studies of restoration of touch sensitivity have indicated that only minimal function 
is detected, even 10 years after partial-thickness lenticule transplantation from a human donor cornea, ${ }^{41}$ showing the feasibility of using biointeractive materials to induce rapid innervation.

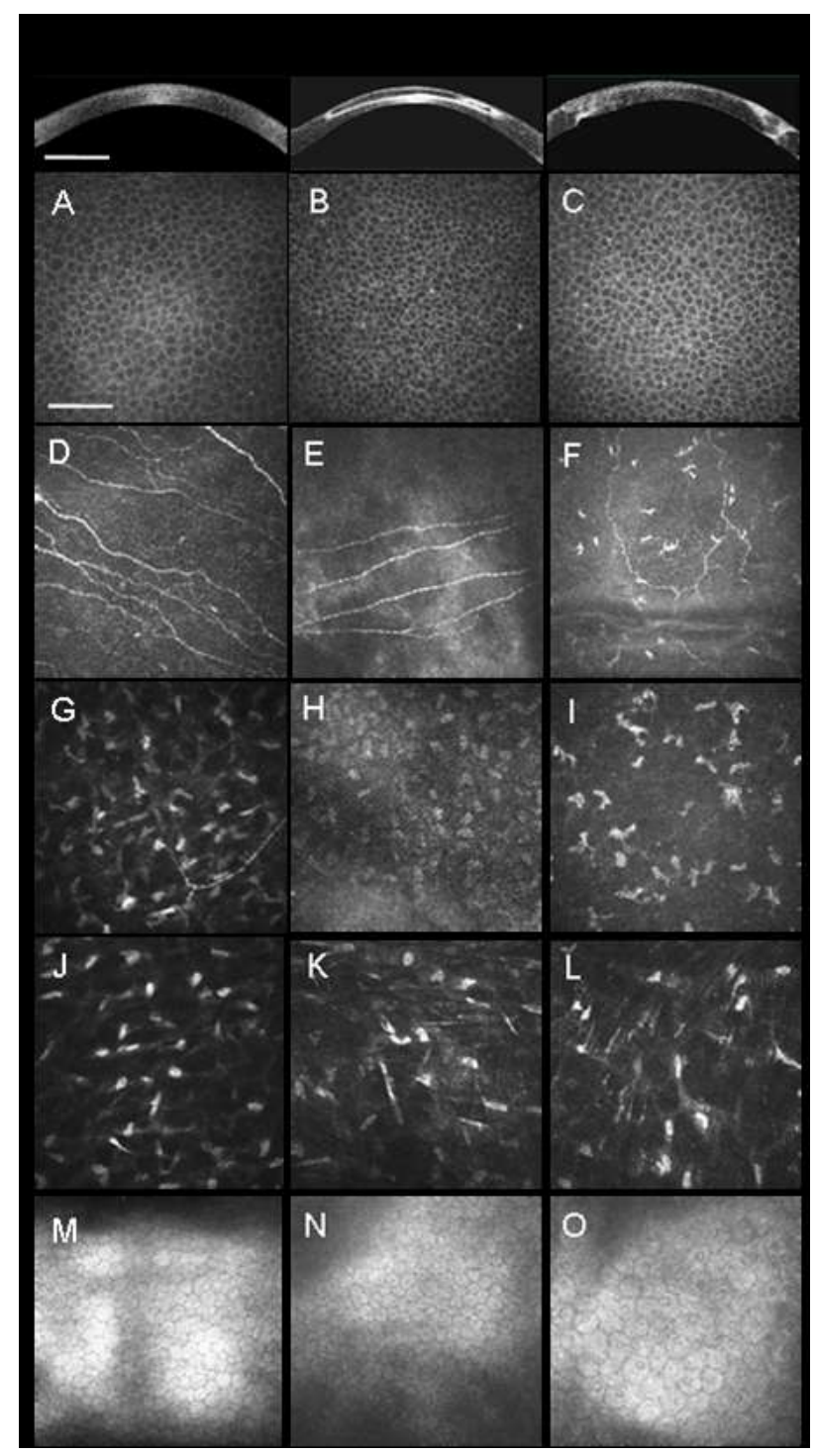

Fig. 2. Corneal features in a healthy, unoperated subject, alongside those of operated patients, at 24 months after implantation of a biosynthetic cornea or a human donor cornea. (Top row): Optical coherence tomography (OCT) images of a healthy cornea, biosynthetic implant, and human donor transplant by lamellar keratoplasty. Areas of wound-healing activity exhibit high reflectivity (white areas). (A to $\mathrm{O}$ ): In vivo confocal microscopy (IVCM) images. Intact epithelium of the unoperated cornea (A), regenerated corneal epithelial cells on the implant surface (B), and regenerated epithelium of the penetrating graft (C). Regenerated nerves (E) at the subbasal epithelium in an implanted cornea were parallel and morphologically similar to the normal cornea (D), whereas regenerated subbasal nerves were also observed in a cornea transplanted with human donor tissue $(\mathrm{F})$. Anterior stromal cell (keratocyte) nuclei (G to I) and posterior keratocytes ( $\mathrm{J}$ to L) were present, with varying density, in all corneas. The endothelium ( $\mathrm{M}$ to $\mathrm{O}$ ) in all corneas exhibited a characteristic mosaic pattern. Scale bars, $2 \mathrm{~mm}$ (OCT), $100 \mathrm{~mm}$ (IVCM). (Reprinted from Fagerholm $\mathrm{P}$, et $\mathrm{al}^{39}$ with permission of the American Association for the Advancement of Science.) 
Whether or not such rapid innervation is desirable $\mathrm{h}$ yet to be determined. Using multifunctional dendrimers in place of TERP as the collagen crosslinker, Duan and Sheardown showed overall improved mechanical strength of their hydrogels. ${ }^{42,43}$ In addition, the presence of the additional functional groups allowed the gels to be modified with large and tunable amounts of biologically relevant functional groups. The maximum achievable YIGSR concentration of $3.1 \mathrm{x}$ $10-2 \mathrm{mg} / \mathrm{ml}$ collagen is significantly greater than that obtained previously using the PNiPAAm based crosslinking agent at $1.6 \times 10-6 \mathrm{mg} / \mathrm{mg}$ of collagen. ${ }^{44}$

More recently, Liu et al showed that biologically interactive corneal substitutes could also be fabricated from interpenetrating polymeric networks of collagen and a synthetic phosphorylcholine (lipid). ${ }^{45}$ In this case, one network comprised of collagen (either porcine or recombinant human) crosslinked with 1-ethyl-3-(3-dimethyl aminopropyl) carbodiimide (EDC) and N-hydroxysuccinimide (NHS). The other network consisted of PEG diacrylate crosslinked 2methacryloyloxyethyl phosphorylcholine (MPC). The resulting hydrogels showed an overall increase in mechanical strength beyond that of both original component and enhanced stability against enzymatic digestion by collagenase or ultraviolet light degradation. More importantly, these constructs retained the full biointeractive and cell-friendly properties of collagen in promoting corneal cell and nerve in-growth and regeneration in both normal animal models and alkali-burnt corneas, despite MPCs known anti-adhesive properties. These hydrogels had refractive indices, white light transmission and backscatter comparable or superior to those of human cornea. Glucose and albumin permeability were also comparable to those of human corneas.

Recently, the porcine collagen component of the hydrogel has been substituted with recombinant human collagen, resulting in a fully-synthetic implant that is free from the potential risks of disease transmission (eg, prions) present in animal source materials. Recent full-thickness collagen MPC implants into guinea pig corneas showed for the first time, by electrophysiology, that various subtypes of corneal sensory nerves regenerated and innervated the implants by 8 months postoperatively, ie, the nerves were functional. ${ }^{46}$ This was in addition to the reconstitution of corneal tissue components within the implant by the in-growth of cells from endogenous progenitors. Similarly, recombinant human collagen-MPC implants in alkali-burnt rabbits also showed extensive regeneration. Collagen-MPC implants, compared to collagen-only implants, were able to prevent neovascularization. ${ }^{47}$

Bioactive collagen-based corneal substitutes can also incorporate micro-or nanoparticles that would release drugs to possibly treat existing conditions, thereby extending their functionality to a wider number of clinical indications. For example, the incorporation of a porous silica dioxide 
nanoparticle-encapsulated antiviral drug, Acyclovir, within a collagen-MPC hydrogel, was able to sustain drug release over 10 days to suppress viral activity in vitro. ${ }^{48}$ In the future, such composite corneal constructs might be useful for prevention of viral reactivation and re-infection in high risk transplants such as of herpetic host corneas during surgery.

\section{Decellularized Corneas as Scaffolds}

The recent use of decellularized corneal stromas, eg, from bovine corneas ${ }^{49}$ for seeding stromal cells, potentially allows for a "ready-made" scaffold with the necessary mechanical properties for reconstruction of a multi-layered human corneal equivalent. While human cadaveric corneas or animal corneas can be used, the porcine cornea appears particularly attractive because of its anatomic similarity to the human cornea. ${ }^{50}$ Cell components of the cornea are the source of the antigens of major histocompatibility complex responsible for allograft/xenograft rejection in various tissues (see section V). Both the antigen-specific (adaptive) and non-antigen-specific (innate) immune responses are thought to be minimized through removal of the cellular components of the cornea, although antibody responses to xenoantigen remain a possibility. Repopulation of the donor by recipient cells would be expected if the graft is accepted. ${ }^{51}$

Recently, several groups have succeeded in preparing an acellular corneal stroma using nonionic detergent and/or several enzymes. They reported that the matrix structure of decellularized corneal stroma was preserved compared with that of native cornea. ${ }^{49,51-54}$ To eliminate the toxic effect of chemicals, Hashimoto and coworkers used high-hydrostatic pressurization (HHP) to decellularize porcine corneas, which were then transplanted into rabbit corneas. ${ }^{55}$ No immune reaction was observed and the turbid corneas became clear. Lee et al used freezing-thawingcentrifugation of porcine cornea to the remove cells from the cornea while preserving the stromal architecture. ${ }^{56}$ Recently, Gonzalez-Andrades et al showed that strong salt solutions (1.5 M sodium chloride) to generate an acellular corneal stroma with adequate histologic and optical properties and human keratocytes were able to penetrate and spread within this scaffold with appropriate levels of cell differentiation. ${ }^{54}$

Despite the potential of these technologies, it should be noted that xenogeneic transplantation or use of poor quality cadaveric human corneas that cannot be used as living allografts will still pose the risk of disease transmission and will require screening, which will be costly.

\section{Cell-Based Regenerative Therapies}


Regeneration of the human cornea using any of the above methods requires regeneration of one or more corneal components, such as the epithelium and stromal fibroblasts, and relies upon the host or patient having a sufficient population of stem or progenitor cells. However, in a number of conditions, the patient's stem cell supply is depleted, eg, in ocular surface disorders, such as chemical/thermal injuries, Stevens-Johnson syndrome, pterygium, or severe microbial infections. In these situations, persistent corneal epithelial defects can occur, or unwanted conjunctival epithelial cells could move centrally accompanied by chronic inflammation, stromal scarring, and neovascularization. This condition is referred to as limbal epithelial stem cell deficiency (LSCD).

LSCD can be total or partial. At present, the most effective treatment available is correction by stem cell transplantation. ${ }^{57}$ If the damage extends beyond the epithelial layer into the stroma and/or endothelium, the patient receives a follow-on corneal allograft transplantation. Kenyon and in 1989 pioneered the use of human corneal limbal epithelial stem cells for treatment of ocular surface disorders. ${ }^{58}$ Figure 3 summarizes the transplantation strategies commonly used to treat the different forms of LSCD.

Pelligrini and coworkers used cultured sheets of epithelium derived from a $1.00 \mathrm{~mm}^{2}$ biopsy of healthy autologous tissue in two cases and showed improved vision in both patients. Two years later, both patients still had a stable corneal epithelium and an absence of vascularization, and had improved visual acuity with reduced symptoms of ocular pain and photophobia. ${ }^{59}$ Since then, many other groups have reported beneficial results from autologous transplantation of corneal limbal epithelial stem cells to treat ocular surface disorders. ${ }^{60-62}$

Where both eyes have LSCD, allografted stem cells have been used. In these cases, LESCs have been cultured for transplantation from living related or cadaveric donor corneas. ${ }^{63}$ The results have been promising in terms of improvement in ocular surface comfort and vision. ${ }^{64}$ However, the mechanism of therapeutic efficacy remains unknown, as there is no evidence of long-term donor tissue survival. ${ }^{65}$ The disadvantage of this technique is that the patient is required to undergo systemic immunosuppression, and even then, the donor cells do not survive over the long term. This has led to a search for autologous, noncorneal cell sources. Inatomi et al reported the successful autologous reconstruction of the corneal surface by transdifferentiation of oral mucosal epithelium. ${ }^{66}$ The authors contend that the use of autologous cells may be safer than allogenic grafts for ocular resurfacing, in particular for younger patients with the most severe ocular surface disorders. However, it should be noted that all transplanted eyes had some peripheral corneal 
neovascularization. Other proposed sources of stem cells include hair follicle bulge derived stem cells $^{67}$ and umbilical mesenchymal cells. ${ }^{68}$

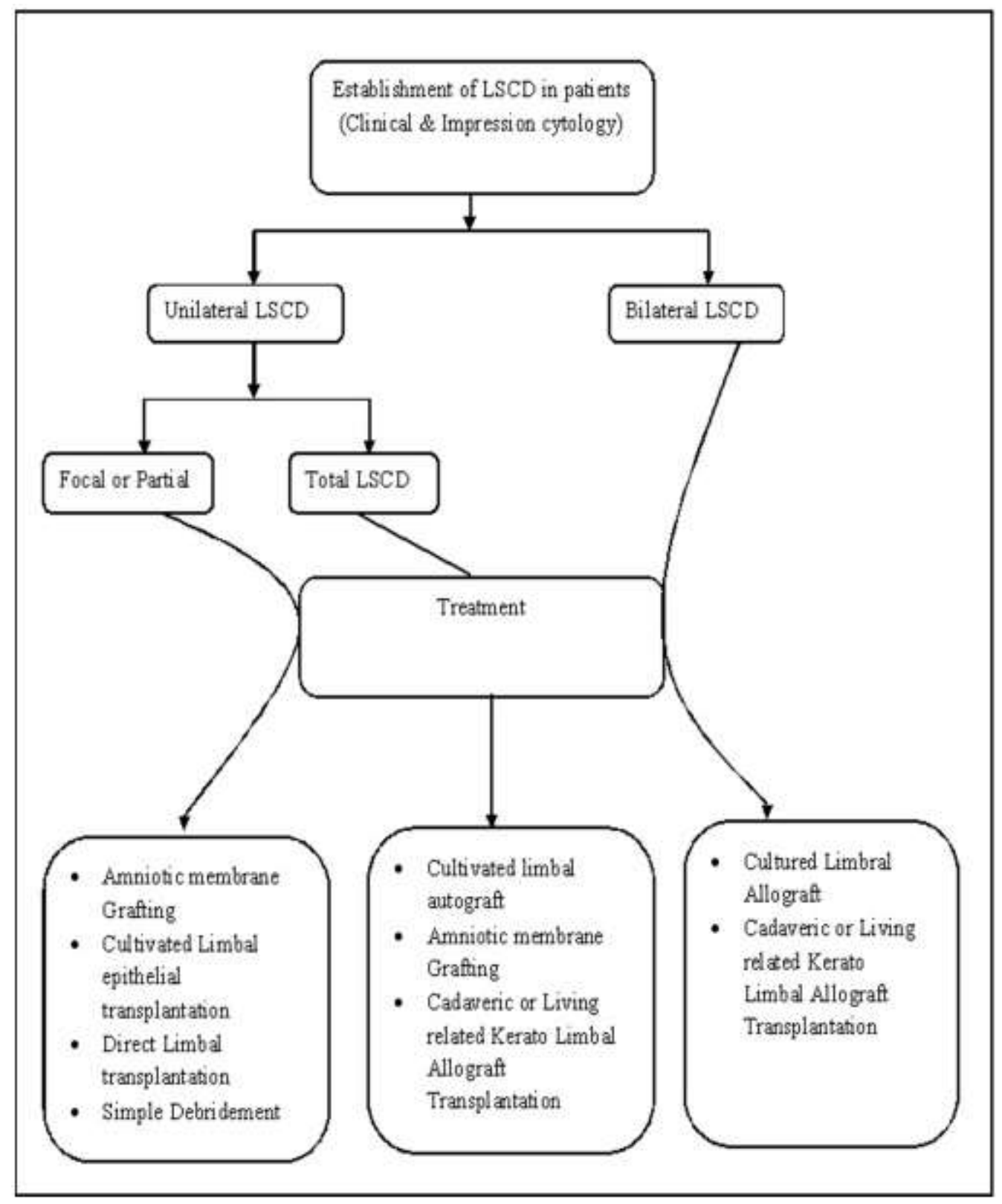

Figure 3. Transplantation strategies commonly used to treat LSCD

Other than direct transplantation of limbal grafts, obtained by biopsy, limbal cells have been expanded in culture and then transplanted as monolayer sheets or as differentiated epithelia. A range of substrates have been tested (Table 1), and several of these are described in detail below. 


\section{A. Corneal Epithelial Reconstruction}

Use of fetal membranes as a surgical material for skin transplantation were first reported in $1910 .^{81,82}$ They were first used in ophthalmic surgery for conjunctival tissue loss and repair of symblepheron. ${ }^{83}$ The use of human amniotic membrane (HAM) as a carrier for limbal stem cells for transplantation was also pioneered by Tseng. ${ }^{84}$

HAM forms the inner wall of the membranous sac that surrounds and protects the embryo during gestation. ${ }^{85}$ It is a translucent membrane whose structure consists of a single layer of epithelial cells attached to a thick basement membrane and an avascular stromal matrix. ${ }^{86}$ Amniotic membrane can range in thickness from $0.02 \mathrm{~mm}$ to $0.5 \mathrm{~mm},{ }^{82}$ and it remains devoid of blood vessels in vivo despite its close proximity to the highly vascular chorionic membrane. ${ }^{86}$ Essentially, when stripped of its cell population, HAM essentially acts as a decellularized scaffold.

Unlike decellularized scaffolds, however, HAM has several additional unique characteristics that make it a popular surgical tool in corneal ocular surface reconstruction, eg, antiinflammatory, antiscarring and antiangiogenic properties. ${ }^{86}$ Hao and coworkers showed that both human amniotic epithelial and mesenchymal cells express interleukin-1 receptor antagonist, all four members of the family of tissue inhibitors of metalloproteinase (TIMP), collagen XVIII, and interleukin-10, thus providing an explanation for the anti-inflammatory and antiangiogenic properties of amniotic membrane. ${ }^{87}$ HAM also reduces scarring by suppressing TGF- $\beta$ signalling and myofibroblast differentiation ${ }^{88}$ and also produces growth factors that can stimulate epithelialization. ${ }^{89}$ Koizumi et al demonstrated that EGF, transforming growth factor $\alpha$ (TGF $\boldsymbol{\alpha})$, keratinocyte growth factor (KGF), hepatocyte growth factor (HGF), basic fibroblast growth factor (bFGF) and TGF- $\beta$ were expressed in amniotic membrane and may facilitate re-epithelialization. ${ }^{77}$ Moreover, HAM can act as a basement membrane that enables the migration of cells through the presence of laminin isoforms. ${ }^{82}$ HAM is now extensively used in ophthalmic surgery for corneal and conjunctival reconstruction. ${ }^{86}$ Because of its healing properties, it can be used as a biological bandage to cover inflamed or exposed areas caused by surgery or injury. In these procedures, the amniotic membrane is sutured with the epithelial side facing the ocular surface. In corneal reconstruction, the amniotic membrane is used to treat LESC deficiencies, perforations, bullous keratopathy, and corneal ulcers. ${ }^{86}$

In 2003, Sangwan and coworkers established a coculture system of limbal epithelial cells and conjunctival epitheial cells and successfully treated patients with bilateral partial LSCD. ${ }^{69}$ Limbal and conjunctival tissue was harvested from the healthy eye and used to generate two sheets of composite epithelium consisting of central limbal and peripheral conjunctival cells. The limbal 
tissues were explanted in the central region while the conjunctival tissues were explanted on the periphery of the de-epithelialized HAM and nurtured using human corneal epithelial cell medium.

Despite the successful use of HAM, however, donated human tissues require careful screening, sterilization and preservation to prevent disease transmission. The use of synthetic, carrier-free constructs and biodegradable polymers can potentially avoid this risk. Alternatives tested are described below.

\section{B. Biomaterials-Assisted Carrier-Free Transplantation of Corneal Cell Sheets}

Okano's group in Japan developed an ingenious culture system based on synthetic polymer surfaces that allows for essentially carrier-free sheets of corneal epithelium to be cultured for transplantation. ${ }^{78}$ For the reconstruction of the corneal epithelial sheets, limbal epithelial stem cells can be isolated and cultured on top of temperature-responsive Poly (N-Isopropylacrylamide)

(PNIPAAm) grafted onto tissue culture plastic. At $37^{\circ} \mathrm{C}$, the PNIPAAm is in the gel state, forming a sheet on which the stem cells proliferate and then differentiate. The material can be harvested, by temperature reduction to $20^{\circ} \mathrm{C}$ for $30 \mathrm{~min}$ when the gel converts to the sol (liquid) state, releasing the cell sheets, along with their deposited ECM. These can be easily manipulated to adhere to the host corneal stroma without the need of sutures. In comparison to cells harvested by treatment with enzymes or Dispase ${ }^{\mathrm{TM}}$, corneal epithelial cell sheets fabricated on temperature-responsive culture dishes are less fragile and contain both cell-to-cell junction and ECM proteins that can be damaged during removal from the solid culture support. In this way, a well-formed epithelial sheet can be transplanted without the need for any carrier substrate, such as amniotic membrane or fibrin gel. In patients receiving corneal epithelial cell sheet transplantation, the corneal surface remains clear with significantly improved visual acuity even after 1 year post-surgery. ${ }^{78}$

To completely eliminate the need to detach cells from the growth surface, attempts have been made to grow human LESCs directly on contact lenses for subsequent transfer to the eye. Desphande and coworkers used a plasma polymer-coated contact lens to aid cell attachment. While rabbit LESCs attached and could subsequently be transferred to a rabbit corneal organ culture model, human limbal epithelial cells required detachment using enzymes. ${ }^{72}$ Notara and coworkers used acrylic acid polymerization to coat the inner surface of a bandage contact lens for the delivery of limbal epithelial cells to patients. ${ }^{74}$ Primary limbal epithelial cells were grown directly on the contact lens surface. ${ }^{74}$ This methodology provides a culture surface, a transport vehicle, and a method to immobilize the cells on the eye while protecting them when in position. The results suggested that these surfaces could be used successfully for the serum-free expansion of human 
limbal epithelial cells. Di Girolamo and coworkers successfully cultured human epithelial cells from a tissue explant on a noncoated contact lens and transferred the cells onto the eyes of three patients with LSCD to restore a transparent corneal epithelium. ${ }^{73}$

A fibrin sealant produced from combining fibrinogen and thrombin has been used as a substrate for LESC growth. It is particularly useful in this context, as it is a quickly degradable, natural substrate. ${ }^{70,90,91}$ Another distinct advantage of this method is that both constituents of the cross-linked fibrin gels can be of human origin, providing the potential for an autologous bioengineered tissue. However, the use of fibrin gels may not be appropriate when a population of stem cells must be maintained, as it has been shown to affect cells by causing differentiation. Han et al reported that all cells cultivated in a fibrin gel stained positively for cytokeratin 3 , a differentiated epithelial cell marker. ${ }^{91}$

Silk fibroin is a structural protein obtained from the cocoon of the silkworm Bombyx mori. It is a particularly useful material in corneal bioengineering, as it displays a nonimmunogenic response on implantation in vivo, is mechanically robust, transparent, and easy to handle, and has controlled degradation rates. ${ }^{79}$ It has also been shown to support the growth of limbal epithelial cells in serum-free conditions to the same extent as tissue culture plastic. ${ }^{80}$ Nanopatterning technology allows surface modification of the silk fibroin, which could provide guidance to the migration and alignment of cells seeded on and in the corneal scaffolds. However, an important point to consider is the cost of such a natural material, which is considerably greater than the cost of synthetic materials.

Collagen, a popular, naturally derived polymer has also been tested as a carrier for corneal LESCs. Vitrified collagen membranes, produced via a three-stage sequence of gelation, vitrification, and rehydration, have been fabricated as $20-50 \mu \mathrm{m}$ transparent membrane with enhanced mechanical properties. ${ }^{92}$ McIntosh Ambrose et al were able to culture human limbal epithelial cells, bovine fibroblasts, and fabricated rabbit endothelial cells on the surface of these vitrified collagen membranes. ${ }^{92}$ They found that limbal epithelial cells expressed markers of both differentiated corneal epithelial cells (cytokeratin 3, cytokeratin 12, and connexin 43) and putative stem cells (p63 and ABCG2), suggesting that the membranes supported both stem cells and differentiated corneal epithelial cells. Dravida et al reported the use of carbodiimide-crosslinked recombinant human collagen type III as substrates and potential carriers for LESCs. ${ }^{75}$ The thin hydrogels had a refractive index and transmission and backscatter properties that were similar to that of native cornea, and LESCs were able to stratify and express putative stem cell and differentiated cell type markers in a fashion similar to cells on AM. 


\section{Corneal Endothelial Reconstruction}

Corneal endothelial replacement is fast becoming a popular surgical technique, as it replaces only the damaged or diseased endothelial layer. As such, biomaterials have now also been tested for their efficacy in supporting corneal endothelial proliferation and as carriers. Early carriers include stripped Descemet membrane. Other carriers tested include the range of materials used for LESCs. Recombinant human collagen has also been tested as a carrier, but unlike the case with LESC, corneal endothelial cells did not grow well on the recombinant human type III collagen, although they grew on recombinant human type I membranes. ${ }^{93}$

Corneal endothelial cells have recently become a popular target for cell seeding, for example, on lamellar matrices, with the goal of manufacturing grafts for lamellar keratoplasty. Primary endothelial cells are more difficult to cultivate than other cell types because of their minimal proliferative capacity. Several groups have been working on overcoming these problems.

Joyce discovered that proliferative capacity is mediated by a G1-phase inhibition of the endothelial cell cycle. ${ }^{94}$ It could have been demonstrated that endothelial cells deriving from younger donors showed a higher proliferative capacity compared to cells of elderly donors. ${ }^{95}$ Importantly, the Joyce group had developed a culture medium for corneal endothelial cells in the meantime, widely adopted through other research groups, improving the cultivation process of these cells and allowing more in-depth studies on human primary cells. ${ }^{95}$

As corneal endothelial cells are crucial to maintain the transparency of the entire cornea, loss of these cells below a critical threshold unavoidably results visual acuity loss up to blindness. To prevent corneas from developing opaqueness through developing edema, sufficient corneal endothelial cell numbers can be maintained by preventing the cells from undergoing apoptosis (programmed cell death). Fuchsluger et al have demonstrated that gene therapy leads to increased cell survival after transduction of corneal endothelial cells with Bcl-xL or p35.$^{96}$ Moreover, they showed that during long-term corneal storage, donor corneas retain significantly higher density of corneal cells and that these cells retained physiological morphology. ${ }^{97}$ While viral vectors were used in this method, ${ }^{98}$ recent approaches turn to biodegradable nanoparticles as carriers of DNA ${ }^{99}$

By targeting Rho/Rho kinase (ROCK) protein signaling using the specific inhibitor, Y27632, which re-creates stem-like conditionsOkumura et al demonstrated enhanced corneal endothelial cell proliferation in vitro, and enhanced endothelial wound healing in vivo, in an animal model. ${ }^{100}$ As they reported, a first human trial is under way to study the effect of this protein in corneal endothelial cell dysfunctions. Similarly, this protein could act as stimulator for cultivation 
of primary corneal endothelial cells with the long-term goal of tissue engineering grafts for lamellar transplantation. ${ }^{101}$ Another approach undertaken by Mehta et al optimizes a culture medium for corneal endothelial cells. ${ }^{102}$

\section{Multi-layer tissue engineered construct}

Several groups of investigators have developed a self-assembly approach to reconstruct multi-layered corneal tissue equivalents, primarily as a research and testing tool, but applications in transplantation have also been discussed. ${ }^{103}$.

The self-assembly technique used by Germain and coworkers adds ascorbic acid to the culture medium to stimulate the secretion of collagen and other extracellular matrix molecules by dermal fibroblast cells. The resulting sheets of extracellular matrix macromolecules are then stacked together to form a stroma, and allowed to further integrate in culture. To complete the construct, an epithelium is seeded on top of the stromal stack. Such constructs were reported to show excellent corneal morphology, and the cells express appropriate tissue-specific markers. ${ }^{104}$

More recently, Carrier et al followed up with a new self-assembled model comprising a stroma consisting of human corneal and dermal fibroblasts. ${ }^{105}$ The authors contend that the combination of the corneal and dermal fibroblasts were more conducive to the formation of a welldifferentiated epithelium that showed higher re-epithelialization rates than just corneal fibroblasts alone. They showed that this model reproduced the microanatomy of the native human cornea. In addition, this model was able to reproduce a mechanistically accurate wound healing process and is therefore useful as a tool for studying wound healing, screening bioactive factors that could modulate wound healing, or as a pre-screen prior to animal testing. ${ }^{105}$ Guo et al characterized the ECM macromolecules deposited by primary human corneal fibroblasts in such self-assembled corneal substitutes. The average culture took 4 weeks to produce a multi-layered construct of about $36 \mu \mathrm{m}$ thickness. ${ }^{106}$ These constructs were highly cellular and are morphologically similar to the stroma of mammalian corneas, with multiple, parallel layers of cells and small fibrillar ECM arrays. The fibrils were between 27 and $51 \mathrm{~nm}$, with a mean of $38.17 .4 \mathrm{~nm}$, compared to the $310.8 \mathrm{~nm}$ reported in adult human corneas (32). ${ }^{106}$

\section{Immunological Considerations}

Studies in mice have shown that each of the three corneal components-- epithelium, stroma, and 
endothelium-- are separately targeted in the rejection process. Donor epithelium is rapidly replaced (15 days in mice) by host epithelium, ${ }^{107}$ while endothelial cell survival predicts whether or not the graft will “take." Plskova et al have calculated that graft failure occurs in mice when $53 \%$ of the endothelium is lost, ${ }^{108}$ indicating that a significant loss of endothelial cells can be accommodated by surviving grafts. Endothelial cell damage is mediated by immune cells (T cells and macrophages), which gain access to the posterior corneal surface by migrating from iris vessels through a fibrin network (clot) in the anterior chamber of the eye (Sosnova-Netukova, unpublished data).

Less is known concerning the relationship between stromal fibroblast survival and overall graft survival as measured conventionally by graft clarity. Allogeneic stromal keratocytes are gradually lost and replaced by infiltrating recipient fibroblasts as well as new vessels, but syngeneic donor stromal keratocytes and allogeneic donor keratocytes in accepted grafts survive long-term. ${ }^{107}$ This indicates that immune rejection of stromal keratocytes occurs in a way similar to endothelial rejection. Clearly, fully functional stromal keratocytes which elaborate collagen and glycosaminoglycans are required for normal corneal physiology. Keratocytes are probably targets of destruction during graft rejection either directly by expressing MHC antigens or indirectly as a result of stromal infiltrating macrophage activity. However, there is little direct information with regard to how much of the corneal opacification is due to loss of keratocyte function or infiltration of the corneal stroma with inflammatory cells, or is a result of stromal edema with accumulation of fluid due to endothelial cell failure. Infiltrating inflammatory and immune cells also probably contribute to the overall stromal opacification due to the local innate and adaptive immune responses. In this case, inflammatory cell extravasation is likely derived from limbal conjunctival vessels.

Loss of the donor epithelium and replacement with host epithelium is not immune-mediated, since donor epithelium was replaced equally rapidly in both syngeneic and allogeneic grafts. ${ }^{107}$ As donor epithelial cells are lost, they are rapidly replaced by host epithelium, due to the strong proliferative potential of epithelial cells in a manner similar to that that occurs with any corneal epithelial injury.

It is clear that much of the immunological damage to donor corneal grafts is based on recognition of alloantigens expressed on donor cells. However, noncellular stromal components may also generate an immune response, particularly across species. Liu et al have recently shown that tissue engineered porcine collagen corneas grafted (full thickness) into mice did not induce a significant $\mathrm{T}$ cell response, but instead generated a low-grade antiporcine collagen Type- 1 antibody response as early as 2 weeks post graft, which continued to rise over several weeks. ${ }^{109}$ However, the main immunological response to the graft was a local innate immune response with formation of a retrocorneal membrane, which ultimately reduced clarity of the transplanted hydrogel. It was unclear whether this was linked to the systemic antibody response or 
simply due to an exaggerated innate immune response within the anterior chamber.

The variable success of limbal stem cell grafts has been attributed both to local inflammatory effects and to immune rejection. Experimentally in mice, while syngeneic grafts were fully accepted, allogeneic limbal stem cell allografts were rejected within 9 days and xenografts even more rapidly. ${ }^{110} \mathrm{It}$ would appear therefore that such grafts suffer the same risk from immune rejection as penetrating grafts, at least in mice.

Recently, the possibility of using stem cell therapy to restore corneal opacification has been considered. Human stem cells have been shown experimentally to promote clearing of the corneal opacity in lumican-deficient mice, and appeared not to induce an immune reaction. ${ }^{111}$ A similar experiment was performed using human adipose-tissue derived stem cells inoculated into the rabbit cornea; no immune response was elicited and the cells survived up to 10 weeks. ${ }^{112}$

These remarkable cross-species experiments require verification, but theoretically it is possible that stem cells, which do not express MHC antigens and express very few surface markers, are "immunologically privileged" cells. When placed in an immunologically privileged tissue, such as the cornea, ${ }^{113}$ stem cells will have "double privilege" and thus greater ability to avoid rejection. This novel concept requires further investigation.

\section{Reinnervation of biointeractive implants}

Despite the high survival rates of allograft transplantation, for many years after surgery the cornea exhibits many changes in its cell structure and functions, particularly in corneal sensitivity.Penetrating and lamellar keratoplasty both need a $360^{\circ}$ corneal incision that cuts stromal corneal nerves and results in a full nerve degeneration of the transplanted cornea.

Nerve regeneration after nerve lesion is present in adult corneas. However, morphology and functional characteristics of regenerated corneal nerves may change significantly. In a first step of neural regeneration, nerve processes distal to the site of lesion, that is, inside the graft, degenerate completely, while the central stumps of cut nerves start to regenerate, and in a second phase form neuroma-like structures near the graft-host border. Weeks afterward, some of the newly formed sprouts of the injured corneal sensory nerves begin to penetrate the denervated host cornea, contributing to the partial restoration of the corneal nerve architecture and sensitivity of the cornea after allograft transplantation. ${ }^{114-117}$

However, even an apparent recovery of corneal innervations is produced, the nerve pattern is rather different from the original corneal nerve architecture. ${ }^{118,119}$ This may be due, at least in part, to the interruption of the uptake by the injured corneal nerve endings of nerve growth signal 
molecules produced by corneal cells. These growth factors, such as NGF, ${ }^{120}$ suffer centripetal axonal transport to the trigeminal somata, where they regulate the expression of genes that encode membrane ion channel and receptor proteins. The absence of these molecular signals in lesioned trigeminal sensory neurons may induce both functional and morphological changes in regenerating neurons, associated to the up- and down-regulation of several genes, such as those encoding ion channels involved in neuronal excitability, which is the basis for ectopic discharges and abnormal responsiveness of lesioned sensory neurons. ${ }^{116,121,122}$ In parallel with the morphological disturbances, lesioned corneal nerves present functional alterations evidenced by an altered threshold and an abnormal responsiveness to natural stimuli of the denervated areas. These abnormalities take months to recover and may never return to normal values.

Thus, denervation produced by nerve cut during keratoplasty causes a reduced (hypoesthesia) or complete (anesthesia) loss of sensitivity inside the transplanted button, followed by a slow recovery associated to the gradual regeneration of sensory nerves inside the graft, ${ }^{123,124}$ which may be induced by an enhanced local production of nerve growth factors after corneal surgical injury. This may explain, at least in part, the enhanced healing and sensory recovery exerted by exogenous NGF (provided by topical treatment or by transplantation NGF-rich tissues as amniotic membrane) in neuropathic corneal ulcers and limbal stem cell deficiency. ${ }^{120,125,126}$.

In addition to the reduced sensitivity observed after nerve lesion, spontaneous abnormal sensations (dysesthesias), including pain and dry eye sensations, also develope after corneal surgery. These abnormal sensations may be due to the activation of nonlesioned nerve endings in the host cornea by inflammatory mediators released after surgery, and also to the ectopic activity of regenerating sensory nerve stumps, similar to the aberrant sensations originated by neuromas at a lost limb ('phantom limb'). ${ }^{127}$

Transplanted corneas may remain anesthetic for years, and sometimes the recovery of sensitivity is restricted to the periphery of the implant. This recovery of corneal sensitivity is directly associated with the degree of graft reinnervation and depends mainly on the type of primary disease underlying keratoplasty. In this sense, it is expected to have better sensitivity recovery after corneal transplant when the host corneal tissue and nerves are in a better condition, as in keratoconus. On the contrary, graft reinnervation and recovery of sensitivity recovery is expected to be worst when surgery is performed in a host cornea with a poor trophic status, as in several systemic and genetic diseases and injuries. Recovery is especially poor in such ocular infections as herpetic keratitis, where corneal innervation and sensitivity are altered in the host cornea before the surgical intervention. Considering the well-established idea that an adequate functional innervation 
is essential to preserve the trophic condition of the corneal tissue, attention should be paid to the recovery of corneal innervation after keratoplasty, which may be a key point to guarantee an adequate corneal trophism after transplantation and may determine corneal graft survival.

Several morphological studies have described corneal nerve regeneration after keratoplasty performed with allogeneic tissue ${ }^{117,128,129}$ and bioengineered corneal substitutes ${ }^{38,40}$ in animal and human models. Recovery of touch corneal sensitivity at different times after keratoplasty has been also studied. ${ }^{38,128,130,131}$ The reported results suggest that nerve regeneration is present both in allograft transplants and artificial implants, being even faster in the artificial corneal substitutes. ${ }^{40}$ Functional evaluation of corneal nerves regenerated into collagen-based artificial corneas showed that corneal nerves inside the implant are fully functional at 8 months after surgery and present normal electrophysiological responses to natural stimulation (mechanical, chemical, heat and cold stimuli) of the corneal surface. ${ }^{46}$

\section{Conclusion}

Significant and exciting developments have taken place in regenerative medicine-based approaches to replace partial or the full-thickness areas of damaged or diseased corneas in the past several years. Biomaterials have been developed to assist in these reparative procedures, from keratoprostheses with regenerative capacities to implants that are designed as interactive scaffolds to promote endogenous regeneration. Biomaterials derived from natural, decellularized tissue to fabricated constructs have also been used as substrates for delivery of exogenous stem cell grafts. Issues that have to be considered are immunological implications as well as the importance of reinnervation of grafts. However, taken together, the different approaches may soon be able to supplement the supply of post-mortem human corneas harvested for transplantation, or allow restoration of diseased or damaged corneas that cannot be treated by currently available techniques.

\section{References}

1. Whitcher JP, Srinivasan M, Upadhyay MP. Corneal blindness: a global perspective. Bull World Health Organ 2001;79:214-21

2. Cosar, CB, Sridhar MS, Cohen EJ, et al. Indications for penetrating keratoplasty and associated procedures, 1996-2000. Cornea 2002;21:148-51 
3. Edwards M, Clover GM, Brookes N, et al. Indications for corneal transplantation in New Zealand: 1991-1999. Cornea 2002;21:152-5

4. Dada T, Sharma N,Vajpayee RB. Indications for pediatric keratoplasty in India. Cornea 1999;18:296-8

5. Gupta V, Gupta A, Bambery P. Vogt-Koyanagi-Harada syndrome following injuryinduced progressive vitiligo. Indian J Ophthalmol 2001;49:53-5

6. Knickelbein JE, Hendricks RL, Charukamnoetkanok P. Management of herpes simplex virus stromal keratitis: an evidence-based review. Surv Ophthalmol 2009;54:226-34

7. Williams KA, Esterman AJ, Bartlett C, et al. How effective is penetrating corneal transplantation? Factors influencing long-term outcome in multivariate analysis. Transplantation 2006;81:896-901

8. Muraine MC, Collet A, Brasseur G. Deep lamellar keratoplasty combined with cataract surgery. Arch Ophthalmol 2002;120:812-5

9. Claesson M, Armitage WJ, Fagerholm P, Stenevi U. Visual outcome in corneal grafts: a preliminary analysis of the Swedish Corneal Transplant Register. Br J Ophthalmol 2002; $86: 174-80$

10. Houff SA, Burton R C, Wilson RW, et al. 1979. Human-to-human transmission of rabies virus by corneal transplant. N Engl J Med 1979;300:603-4

11. Duffy P, Wolf J, Collins G, et al. 1974. Letter: Possible person-to-person transmission of Creutzfeldt-Jakob disease. N Engl J Med 1974;290:692-3

12. Wilhelmus KR, Stulting RD, Sugar J, Khan MM. 1995. Primary corneal graft failure. A national reporting system. Medical Advisory Board of the Eye Bank Association of America. Arch Ophthalmol 1995;113:1497-1502

13. Carlsson DJ, Li F, ShimmuraS, Griffith M. 2003. Bioengineered corneas: how close are we? Curr Opin Ophthalmol 2003;14:192-7

14. Myung D, Duhamel P-E, Cochran JR, et al. Development of hydrogel-based keratoprostheses: a materials perspective. Biotechnol Prog 2008;24:735-41

15. Gomaa A, Comyn O, Liu C. Keratoprostheses in clinical practice - a review. Clin Experiment Ophthalmol 2010;38:211-24

16. Rafat MA, Hackett J M, Fagerholm P, Griffith M. Artificial cornea, in Dartt DA, Besharse J, Dana R (eds). Encyclopedia of the eye. Boston MA, Academic Press

17. Wallace C, Jacob JT, Stoltz A, et al. Corneal epithelial adhesion strength to tetheredprotein/peptide modified hydrogel surfaces. J Biomed Mater Res A 2005;72:19-24 
18. Jacob JT, Rochefort JR, Bi J, Gebhardt BM. Corneal epithelial cell growth over tethered-protein/peptide surface-modified hydrogels. J Biomed Mater Res B Appl Biomat 2005;72:198-205

19. Miyashita H, Shimmura S, Kobayashi H, et al. Collagen-immobilized poly(vinyl alcohol) as an artificial cornea scaffold that supports a stratified corneal epithelium. J Biomed Mater Res B Appl Biomat 2006;76:56-63

20. Shimmura S, Doillon CJ, Griffith M, Nakamura M, et al. 2003. Collagen-poly(Nisopropylacrylamide)-based membranes for corneal stroma scaffolds. Cornea 2003;22:S81-8

21. Uchino Y, Shimmura S, Miyashita H, et al. 2007. Amniotic membrane immobilized poly(vinyl alcohol) hybrid polymer as an artificial cornea scaffold that supports a stratified and differentiated corneal epithelium. J Biomed Mater Res B Appl Biomat 2007;81:201-6

22. Myung D, Koh W, Bakri A, et al. Design and fabrication of an artificial cornea based on a photolithographically patterned hydrogel construct. Biomed Microdevices 2007; 9:911-22

23. Kobayashi H, Ikada Y. Covalent immobilization of proteins on to the surface of poly(vinyl alcohol) hydrogel. Biomaterials 1991;12:747-51

24. Merrett K, Griffith CM, Deslandes Y, et al. Adhesion of corneal epithelial cells to cell adhesion peptide modified pHEMA surfaces. J Biomat Sci Polymer Ed 2001;12:647-71

25. Aucoin L, Griffith CM, Pleizier G, et al. Interactions of corneal epithelial cells and surfaces modified with cell adhesion peptide combinations. J Biomat Sci Polymer Ed 2002;13:44762

26. Johnson G, Jenkins M, Mclean KM, et al. Peptoid-containing collagen mimetics with cell binding activity. J Biomed Mater Res 2000;51:612-24

27. Legeais JM, Renard G. A second generation of artificial cornea (Biokpro II). Biomaterials 1998;19:1517-22

28. Bruining MJ, Pijpers AP, Kingshott P, Koole LH. Studies on new polymeric biomaterials with tunable hydrophilicity, and their possible utility in corneal repair surgery. Biomaterials 2002;23:1213-9

29. George A, Pitt WG. Comparison of corneal epithelial cellular growth on synthetic cornea materials. Biomaterials 2002;23:1369-73

30. Klenkler BJ, Griffith M, Becerril C, et al. EGF-grafted PDMS surfaces in artificial cornea applications. Biomaterials 2005;26:7286-96

31. Merrett K, Griffith CM, Deslandes Y, et al. 2003. Interactions of corneal cells with transforming growth factor beta 2-modified poly dimethyl siloxane surfaces. J Biomed Mater Res A 2003;67:981-93 
32. Kim MK, Park IS, Park HD, et al. Effect of poly(ethylene glycol) graft polymerization of poly(methyl methacrylate) on cell adhesion. In vitro and in vivo study. $J$ Cataract Refract Surg 2001;27:766-74

33. Myung D, Farooqui N, Zheng L L, et al. Bioactive interpenetrating polymer network hydrogels that support corneal epithelial wound healing. J Biomed Mater Res A 2009;90:70-81

34. Lee KY, Mooney D J. Hydrogels for tissue engineering. Chem Rev 2001;101:186979

35. Hoffman AS. 2002. Hydrogels for biomedical applications. Adv Drug Deliv Rev 2002;54:3-12

36. Amis EJ, Carriere CJ, Ferry JD, Veis A. Effect of $\mathrm{pH}$ on collagen flexibility determined from dilute solution viscoelastic measurements. Int J Biol Macromolecules 1985;7:1304

37. Pierschbacher MD, Ruoslahti E. Influence of stereochemistry of the sequence ArgGly-Asp-Xaa on binding specificity in cell adhesion. J Biol Chem 1987;262:17294-8

38. Fagerholm P, Lagali NS, Carlsson DJ, et al. 2009. Corneal regeneration following implantation of a biomimetic tissue-engineered substitute. Clin Transl Sci 2009;2:162-4

39. Fagerholm P, Lagali NS, Merrett K, et al. A biosynthetic alternative to human donor tissue for inducing corneal regeneration: 24-month follow-up of a phase 1 clinical study. Sci Transl Med 2010;2:46ra61

40. Li F, Carlsson D, Lohmann C, et al. Cellular and nerve regeneration within a biosynthetic extracellular matrix for corneal transplantation. Proc Natl Acad Sci U SA 2003;100:15346-51

41. Kaminski SL, Biowski R, Lukas JR, et al. Corneal sensitivity 10 years after epikeratoplasty. J Refract Surg 2002;18:731-6

42. Duan X, Sheardown H. Crosslinking of collagen with dendrimers. J Biomedical Materials Research. Part A 2005;75:510-8

43. Duan X, Sheardown H. Dendrimer crosslinked collagen as a corneal tissue engineering scaffold: mechanical properties and corneal epithelial cell interactions. Biomaterials 2006; 27:4608-17

44. Li F, Griffith M, Li Z, et al. Recruitment of multiple cell lines by collagen-synthetic copolymer matrices in corneal regeneration. Biomaterials 2005;26:3093-104

45. Liu W, Deng C, Mclaughlin CR, et al. Collagen-phosphorylcholine interpenetrating network hydrogels as corneal substitutes. Biomaterials 2009;30:1551-9 
46. Mclaughlin, CR, Acosta MC, Luna $\mathrm{C}$ et al.. Regeneration of functional nerves within full thickness collagen-phosphorylcholine corneal substitute implants in guinea pigs. Biomaterials 2010;31:2770-8

47. Hackett JM, Lagali N, Merrett K, et al. Biosynthetic corneal implants for replacement of pathologic corneal tissue: performance in a controlled rabbit alkali burn model. Invest Ophthalmol Vis Sci 2011;52:651-7

48. Bareiss B, Ghorbani M, Li F, et al.. Controlled release of acyclovir through bioengineered corneal implants with silica nanoparticle carriers. Open Tissue Eng Regen Med J 2010;3:10-7

49. Ponce Márquez S, Martínez VS, Mcintosh Ambrose W, et al. Decellularization of bovine corneas for tissue engineering applications. Acta Biomaterialia 2009;5:1839-47

50. Heinz C, Eckstein A, Steuhl K-P, Meller D. 2004. Amniotic membrane transplantation for reconstruction of corneal ulcer in graves ophthalmopathy. Cornea 2009;23:524-6

51. Hu X, Lui W, Cui L, et al. Tissue engineering of nearly transparent corneal stroma. Tissue Eng 2005;11:1710-7

52. Ignacio TS, Nguyen TTB, Sarayba MA, et al. A technique to harvest Descemet's membrane with viable endothelial cells for selective transplantation. Am J Ophthalmol 2005;139: $325-30$

53. Choi JS, Williams JK, Greven M, et al. Bioengineering endothelialized neo-corneas using donor-derived corneal endothelial cells and decellularized corneal stroma. Biomaterials 2010;31:6738-45

54. Gonzalez-Andrades M, De La Cruz Cardona J, Ionescu AM, et al. Generation of bioengineered corneas with decellularized xenografts and human keratocytes. Invest Ophthalmol Vis Sci 2011;52:215-22

55. Hashimoto Y, Funamoto S, Sasaki S, et al. Preparation and characterization of decellularized cornea using high-hydrostatic pressurization for corneal tissue engineering. Biomaterials 2010;31:3941-8

56. Lee SH, Chun YS, Kim JC. The study of characteristics of acellular porcine cornea using freezing-thawing-centrifugation. J Korean Ophthalmol Soc 2011;52:86

57. Pauklin M, Fuchsluger TA, Westekemper H, et al. Midterm results of cultivated autologous and allogeneic limbal epithelial transplantation in limbal stem cell deficiency. Dev Ophthalmol 2010;45:57-70

58. Kenyon KR, Tseng SC. Limbal autograft transplantation for ocular surface disorders. Ophthalmology 1989;96:709-22; discussion:722-3 
59. Pellegrini G, Traverso CE, Franzi AT, et al. Long-term restoration of damaged corneal surfaces with autologous cultivated corneal epithelium. Lancet 1997;349:990-3

60. Schwab IR, Reyes M, Isseroff RR. Successful transplantation of bioengineered tissue replacements in patients with ocular surface disease. Cornea 2000;19:421-6

61. Tsai RJ, Li LM, Chen JK. 2000. Reconstruction of damaged corneas by transplantation of autologous limbal epithelial cells. N Engl J Med 2000;343:86-93

62. Nakamura T, Inatomi T, Sotozono C, et al. Successful primary culture and autologous transplantation of corneal limbal epithelial cells from minimal biopsy for unilateral severe ocular surface disease. Acta Ophthalmol Scand 2004;82:468-71

63. Tsai RJ-F, Tseng SCG. Human allograft limbal transplantation for corneal surface reconstruction. Cornea 1994;13:389-400

64. Shortt AJ, Secker GA, Notara MD, et al. Transplantation of ex vivo cultured limbal epithelial stem cells: a review of techniques and clinical results. Surv Ophthalmol 2007;52:483-502

65. Daya SM, Watson A, Sharpe JR, et al. Outcomes and DNA analysis of ex vivo expanded stem cell allograft for ocular surface reconstruction. Ophthalmology 2005;112:470-7

66. Inatomi T, Nakamura T, Kojyo M, et al. Ocular surface reconstruction with combination of cultivated autologous oral mucosal epithelial transplantation and penetrating keratoplasty. Am J Ophthalmol 2006;142:757-64

67. Meyer-Blazejewska EA, Kruse FE, Bitterer K, et al. Preservation of the limbal stem cell phenotype by appropriate culture techniques. Invest Ophthalmol Vis Sci 2010;51:765-74

68. Liu H, Zhang J, Liu C-Y, et al. Cell therapy of congenital corneal diseases with umbilical mesenchymal stem cells: lumican null mice. PloS One 2010;5:e10707

69. Sangwan VS, Vemuganti GK, Iftekhar G, et al. Use of autologous cultured limbal and conjunctival epithelium in a patient with severe bilateral ocular surface disease induced by acid injury: a case report of unique application. Cornea 2003;22:478-81

70. Rama P, Bonini S, Lambiase A, et al. Autologous fibrin-cultured limbal stem cells permanently restore the corneal surface of patients with total limbal stem cell deficiency. Transplantation 2001;72:1478-85

71. Francis D, Abberton K, Thompson E, Daniell M. Myogel supports the ex-vivo amplification of corneal epithelial cells. Exp Eye Res 2009;88:339-46

72. Deshpande P, Notara M, Bullett N, et al. Development of a surface-modified contact lens for the transfer of cultured limbal epithelial cells to the cornea for ocular surface diseases. Tissue Eng Part A 2009;15:2889-2902 
73. Di Girolamo N, Bosch M, Zamora K, et al. A contact lens-based technique for expansion and transplantation of autologous epithelial progenitors for ocular surface reconstruction. Transplantation 2009;87:1571-8

74. Notara M, Bullett NA, Deshpande P, et al. Plasma polymer coated surfaces for serum-free culture of limbal epithelium for ocular surface disease. J Mater Sci Mater Med 2007;18:329-38

75. Dravida S, Gaddipati S, Griffith M, et al. A biomimetic scaffold for culturing limbal stem cells: a promising alternative for clinical transplantation. J Tissue Eng Regen Med 2008;2:26371

76. Espana EM, Ti SE, Grueterich M, et al. Corneal stromal changes following reconstruction by ex vivo expanded limbal epithelial cells in rabbits with total limbal stem cell deficiency. Br J Ophthalmol 2003;87:1509-14

77. Koizumi NJ, Inatomi TJ, Sotozono CJ,et al. Growth factor mRNA and protein in preserved human amniotic membrane. Curr Eye Res 2000;20:173-7

78. Nishida K, Yamato M, Hayashida Y, et al. Corneal reconstruction with tissueengineered cell sheets composed of autologous oral mucosal epithelium. $N$ Engl J Med 2004;351:1187-96

79. Lawrence BD, Cronin-Golomb M, Georgakoudi I, et al. Bioactive silk protein biomaterial systems for optical devices. Biomacromolecules 2008;9:1214-20

80. Chirila T, Barnard Z, Zainuddin, et al. Bombyx mori silk fibroin membranes as potential substrata for epithelial constructs used in the management of ocular surface disorders. Tissue Eng Part A 2008;14:1203-11

81. Trelford JD, Trelford-Sauder M. The amnion in surgery, past and present. Am J Obstetr Gynecol 1979;134:833-45

82. Dua HS, Gomes JA, King AJ, Maharajan VS. The amniotic membrane in ophthalmology. Surv Ophthalmol 2004;49:51-77

83. De Roth A. Plastic repair of conjunctival defects with fetal membrane. Arch Ophthalmol 1940;23:522-5

84. Kim JC, Tseng SC. Transplantation of preserved human amniotic membrane for surface reconstruction in severely damaged rabbit corneas. Cornea 1995;14:473-84

85. Shortt AJ, Secker GA, Lomas RJ, et al. The effect of amniotic membrane preparation method on its ability to serve as a substrate for the ex-vivo expansion of limbal epithelial cells. Biomaterials 2009;30:1056-65

86. Gomes JA, Romano A, Santos MS, Dua HS. Amniotic membrane use in ophthalmology. Curr Opin Ophthalmol 2005;16:233-40 
87. Hao Y, Ma DH, Hwang DG, et al. Identification of antiangiogenic and antiinflammatory proteins in human amniotic membrane. Cornea 2000;19:348-52

88. Tseng SC, Li DQ, Ma X. Suppression of transforming growth factor-beta isoforms, TGF-beta receptor type II, and myofibroblast differentiation in cultured human corneal and limbal fibroblasts by amniotic membrane matrix. J Cell Physiol 1999;179:325-35

89. Tosi GM, Massaro-Giordano M, Caporossi A, Toti P. Amniotic membrane transplantation in ocular surface disorders. J Cell Physiol 2005;202:849-51

90. Higa K, Shimmura S, Kato N, et al. Proliferation and differentiation of transplantable rabbit epithelial sheets engineered with or without an amniotic membrane carrier. Invest Ophthalmol Vis Sci 2007;48:597-604

91. Han B, Schwab I R, Madsen TK, Isseroff RR. A fibrin-based bioengineered ocular surface with human corneal epithelial stem cells. Cornea 2002; 21:505-10

92. Mcintosh Ambrose W, Salahuddin A, So S, et al. Collagen Vitrigel membranes for the in vitro reconstruction of separate corneal epithelial, stromal, and endothelial cell layers. $J$ Biomed Mater Res B Appl Biomat 2009;90:818-31

93. Mclaughlin CR, Tsai RJ, Latorre MA, Griffith M. Bioengineered corneas for transplantation and in vitro toxicology. Front Biosci 2009;14:3326-37

94. Joyce NC. Proliferative capacity of the corneal endothelium. Prog Retin Eye Res $2003 ; 22: 359-89$

95. Zhu C, Joyce NC. Proliferative response of corneal endothelial cells from young and older donors. Invest Ophthalmol Vis Sci 2004;45:1743-51

96. Fuchsluger TA, Jurkunas U, Kazlauskas A, Dana R. Corneal endothelial cells are protected from apoptosis by gene therapy. Hum Gene Ther 2011;22:549-58

97. Fuchsluger TA, Jurkunas U, Kazlauskas A, Dana R. Anti-apoptotic gene therapy prolongs survival of corneal endothelial cells during storage. Gene Ther 2011;18:778-87

98. Fuchsluger TA, Jurkunas U, Kazlauskas A, Dana R. [Viral vectors for gene delivery to corneal endothelial cells]. Klin Monbl Augenheilkd 2011;228:498-503. German

99. Hu J, Kovtun A, Tomaszewski A, et al A new tool for the transfection of corneal endothelial cells: Calcium phosphate nanoparticles. Acta Biomater 2012;8:1156-63. Epub 2011 Sep 17

100. Okumura N, Koizumi N, Ueno M, et al. The new therapeutic concept of using a rho kinase inhibitor for the treatment of corneal endothelial dysfunction. Cornea 2011;30 Suppl 1:S54-9

101. Okumura N, Ueno M, Koizumi N, et al. Enhancement on primate corneal endothelial cell survival in vitro by a ROCK inhibitor. Invest Ophthalmol Vis Sci 2009;50:3680-7 
102. Peh GS, Beuerman RW, Colman A, et al. Human corneal endothelial cell expansion for corneal endothelium transplantation: an overview. Transplantation 2011;91:811-9

103. Ruberti JW, Zieske JD. Prelude to corneal tissue engineering - gaining control of collagen organization. Prog Retin Eye Res 2008;27:549-77

104. Proulx S, d'Arc Uwamaliya J, Carrier P, et al. Reconstruction of a human cornea by the self-assembly approach of tissue engineering using the three native cell types. Mol Vis 2010;16:2192-201

105. Carrier P, Deschambeault A, Talbot M, et al. Characterization of wound reepithelialization using a new human tissue-engineered corneal wound healing model. Invest Ophthalmol Vis Sci 2008;49:1376-85

106. Guo X, Hutcheon AE, Melotti SA, et al. Morphologic characterization of organized extracellular matrix deposition by ascorbic acid-stimulated human corneal fibroblasts. Invest Ophthalmol Vis Sci 2007;48:4050-60

107. Hori J, Streilein JW. Dynamics of donor cell persistence and recipient cell replacement in orthotopic corneal allografts in mice. Invest Ophthalmol Vis Sci 2001;42:1820-8

108. Plskova J, Kuffova L, Holan V, et al. Evaluation of corneal graft rejection in a mouse model. Br J Ophthalmol 2002;86:108-11

109. Liu L, Kuffova L, Griffith M, et al. Immunological responses in mice to fullthickness corneal grafts engineered from porcine collagen. Biomaterials 2007;28:3807-14

110. Lencova A, Pokorna K, Zajicova A, et al: Graft survival and cytokine production profile after limbal transplantation in the experimental mouse model. Transpl Immunol 2011;24:189-94

111. Du Y, Carlson EC, Funderburgh ML, et al. Stem cell therapy restores transparency to defective murine corneas. Stem Cells 2009;27:1635-42

112. Arnalich-Montiel F, Pastor S, Blazquez-Martinez A, et al. Adipose-derived stem cells are a source for cell therapy of the corneal stroma. Stem Cells 2008;26:570-9

113. Forrester JV, Xu H, Lambe T, Cornall R. Immune privilege or privileged immunity? Mucosal Immunol 2008;1:372-81

114. Rózsa AJ, Guss RB, Beuerman RW. Neural remodelling following experimental surgery of the rabbit cornea. Invest Ophthalmol Vis Sci 1983;24:1033-51

115. Mülle, LJ, Marfur, CF, Kruse F, Tervo TMT. Corneal nerves: structure, contents and function. Exp Eye Res 2003;76:521-42 
116. Belmonte C, Acosta MC, Gallar J. Neural basis of sensation in intact and injured corneas. Exp Eye Res 2004;78:513-25

117. Stachs O, Zhivov A, Kraak R, et al. Structural-functional correlations of corneal innervation after LASIK and penetrating keratoplasty. J Refract Surg 2010;26:159-67

118. Guthoff RF, Wienss H, Hahnel C, Wree A. Epithelial innervation of human cornea: a three-dimensional study using confocal laser scanning fluorescence microscopy. Cornea 2005;24:608-13

119. Yu CQ, Rosenblatt MI. Transgenic corneal neurofluorescence in mice: a new model for in vivo investigation of nerve structure and regeneration. Invest Ophthalmol Vis Sci 2007;48:1535-42

120. Bonini S, Aloe L, Bonini S, et al. Nerve growth factor (NGF): an important molecule for trophism and healing of the ocular surface. Adv Exp Med Biol 2002;506:531-7

121. Black JA, Waxman SG. Molecular identities of two tetrodotoxin-resistant sodium channels in corneal axons. Exp Eye Res 2002;75:193-9

122. Belmonte C, Donovan-Rodriguez T, Luna C, et al. Sodium channel blockers modulate abnormal activity of regenerating corneal sensory nerves. Invest Ophthalmol Vis Sci 2009;50:Arvo abstract No 908

123. Rao GN, John T, Ishida N, Aquavella JV. Recovery of corneal sensitivity in grafts following penetrating keratoplasty. Ophthalmology 1985;92:1408-11

124. Tervo T, Moilanen JAO. In vivo confocal microscopy for evaluation of wound healing following corneal refractive surgery. Prog Ret Eye Res 2003;22:339-58

125. Kruse FE, Rohrschneider K, Volcker HE. Multilayer amniotic membrane transplantation for reconstruction of deep corneal ulcers. Ophthalmology 1999;106:1504-11

126. Touhami A, Grueterich M, Tseng SCG. The role of NGF signaling in human limbal epithelium expanded by amniotic membrane culture. Invest Ophthalmol Vis Sci 2002;43:987-94

127. Belmonte C. Eye dryness sensations after refractive surgery: impaired tear secretion or "phantom" cornea? J Refract Surg 2007;23:598-602

128. Darwish T, Brahma A, Efron N, O'Donnell C. Subbasal nerve regeneration after penetrating keratoplasty. Cornea 2007;26:935-40

129. Patel SV, Erie JC, McLaren JW, Bourne WM. Keratocyte density and recovery of subbasal nerves after penetrating keratoplasty and in late endothelial failure. Arch Ophthalmol 2007; $125: 1693-8$

130. Javaloy J, Aracil A, Belmonte J, Gallar J. [Corneal trophism and sensitivity changes after penetrating keratoplasty]. Arch Soc Esp Oftalmol 2000;75:595-604. Spanish 


\section{Legends}

Table 1. Examples of different substrates used as carriers for expansion and transplantation of corneal limbal epithelial stem cells.

\begin{tabular}{|l|l|l|}
\hline & Substrate $^{\text {Reference }}$ & Application \\
\hline 1 & Human amniotic membrane $^{60,61,69}$ & Clinical \\
\hline 2 & Fibrin $^{70}$ & Clinical \\
\hline 3 & Myogel $^{71}$ & Research \\
\hline 4 & Soft contact lens $^{72}$ & Research \\
\hline & $\begin{array}{l}\text { Soft contact lens } \\
\text { (3) } \\
\text { Recombinant human collagen } \\
\text { hydrogel }^{75}\end{array}$ & Clinical \\
\hline 6 & Corneal stroma $^{76}$ & Research \\
\hline 7 & Culture inserts $^{77}$ & Research \\
\hline 8 & PNIPAAm grafted surfaces $^{78}$ & Research \\
\hline 9 & Silk fibroin $^{79,80}$ & Research \\
\hline
\end{tabular}

2.

3. 